\title{
Critics denounce first genome map as premature
}

\section{San Francisco}

Collaborative Research, Inc. unveiled what it claims to be "the world's first genetic linkage map of the entire human genome" at the 7 October meeting of the American Society of Human Genetics, in San Diego. The Massachusetts company described its achievement as a scientific milestone, a valuable research tool and an avenue into the potentially lucrative production of diagnostic tests for common diseases. The map will appear in the 23 October issue of Cell.

Some of the company's critics, who characterize the map as simply one step in a continuing process, protest that the announcement is premature, amounting only to an act of "scientific merchandising". Orrie M. Friedman, company chairman, defended the move, saying that, as the map is ready for use, Collaborative was obliged to make it public to provide reassurance for its stockholders, credit for its scientists and an important resource for the scientific community.

The linkage map, with an average 10 centimorgan resolution, has emerged

\section{AIDS virus infects another lab worker}

\section{Washington}

The National Institutes of Health (NIH) last week reported the second case of a laboratory worker becoming infected with HIV, the virus causing AIDS (acquired immune deficiency syndrome), through occupational exposure (see Nature 329, 92; 1987). The infection evidently occurred when a worker at a facility under contract to NIH cut his hand while handling concentrated virus.

The worker's injury occurred toward the end of 1985, and the presence of the infection was first detected in May 1986 by an ELISA (enzyme-linked immunosorbent assay) test performed on a sample of the worker's blood. NIH officials and the worker in question were only recently informed of the test results.

Investigators will attempt to isolate and characterize the virus from the infected worker to see if it the same as the one he or she was handling.

A team of safety investigators from NIH and the Centers for Disease Control in Atlanta is in the process of inspecting facilities licensed to handle concentrated quantities of HIV. It has so far concluded that current safety precautions are adequate to protect workers and the public so long as safety procedures are strictly observed.

Joseph Palca from "islands of linkage" within the past several months, said Helen Donis-Keller, director of the project. The group has put 404 polymorphic sites in order on the genome, using DNA from 21 different families supplied by the Centre d'Etude du Polymorphisme Humain $(\mathrm{CEPH})$ in France.

Collaborative's researchers sorted through more than 1,500 single-copy probes from a human DNA library. They found 250 revealing restriction fragment length polymorphisms (RFLPs) with heterozygosity of 40 per cent or more, making them highly informative markers likely to differ between individuals. The rest of the 404 markers came from individual chromosome libraries or were publicly available probes identified by others.

The polymorphic sites were ordered on the genome with the help of two computer program packages independently developed for the project, one by Collaborative scientist Philip Green and the other by MIT mathematician Eric Lander. The programs first compared the markers two by two, sorting them into linkage groups, then ordered the markers within those groups. In many cases the analysis was done with both programs to confirm the final map.

Linkage-groups were localized to specific chromosomes by hybrid panel analysis, in which a probe from a linkage group is hybridized against DNA from various hybrid cell lines, each of which contains an incomplete set of human chromosomes.

Donis-Keller said the map is by no means "complete" and needs more markers to improve resolution and to close gaps that remain on some chromosomes. Nevertheless, there is 95 per cent chance that any new probe will be linked to a known marker.

The map will increase the efficiency with which single-gene disorders can be localized, said Donis-Keller. With a handful of the most informative markers, a disease locus can be localized to a linkage group and then ordered among markers in the region.

In the interests of scientific openness, Collaborative will make its probes freely available for research purposes. It is, however, applying for patents on the probes, and stands to gain if an investigator uses a probe in a way that has commercial applications. In response to cries of commercialism, Friedman calls the plan the best compromise both to benefit the scientific community and to protect the company's shareholders.

The company's main goal in its five-year effort costing nearly $\$ 12$ million has been to produce a tool for the development of diagnostic tests, but the market for tests for the relatively rare single-gene disorders is too small to provide the required return on the investment.

Stock analysts have thus criticized Collaborative on the grounds that its approach to genome mapping has been too grand and expensive, and have in particular criticized the company's failure to capture the market for various diagnostic tests, using publicly available probes whenever possible and concentrating on a few specific diseases.

Friedman defended the company's approach as the "cornerstone of a longterm strategy" to develop diagnostic tests for complex inherited diseases, such as heart disease, cancer, diabetes and psychiatric illness, that may be caused by two or more genes acting independently. $\mathrm{He}$ estimated that the company could increase its present $\$ 13$ million annual turnover (from the sale of various biomedical and pharmaceutical products) to several hundred million dollars with the introduction of tests for these diseases.

The genome map opens the way for the development of such tests, according to Green. With markers spaced across the whole genome, Green believes simultaneous computer-assisted analysis can link a disease trait to more than one locus. Without this approach, data from different families in which a disease is caused by different genes could cancel each other out. The present map, even with its gaps, should be sufficient to begin on such analysis, say the authors of the study.

Nevertheless, the gaps have led some critics to protest at Collaborative's announcement. Ray White, who is compiling a similar map at the Howard Hughes Medical Institute in Salt Lake City, said he considered publication of any map containing gaps to be premature, and added that he is publishing his map one chromosome at a time, as he develops complete linkage groups.

Collaborative officials point out the differences between the goals of the two groups. White is seeking a map with 1-2-centimorgan resolution, for the eventual cloning of disease genes, but Collaborative researchers have sought a map to help them begin on the genetic analysis of complex inherited diseases, on which they now feel ready to embark.

A map comparable to that of Collaborative Research is being developed by $\mathrm{CEPH}$ in Paris. That map will owe much to Ray White who has supplied more RFLPs than any other contributor to the collaborative project. Jean Dausset, who heads CEPH, says that its 10 -centimorgan map will be finished in 1988 . Two weeks ago, he announced plans to distribute the 150 or so probes that will define the map free of charge to any researcher on condition that they are not used commercially.

Marcia Barinaga 